\title{
Waste tires disposal by thermal plasma for power generation and carbon black recovery
}

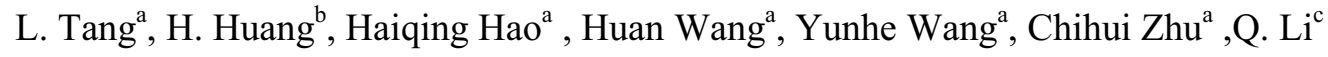 \\ ${ }^{a}$ Department of Civil Engineering, Guangzhou University \\ Guangzhou, China \\ ${ }^{b}$ Department of Environmental Engineering, Guangdong University of Technology \\ Guangzhou, China \\ ${ }^{c}$ Yangjiang building environmental science and technology limited company \\ Yangjiang, China
}

\begin{abstract}
Pyrolysis of waste tires in thermal plasma is studied for the purpose of power generation and recovering carbon black filler. The results of a series of experiments have shown that the main components of the gaseous product are $\mathrm{H}_{2}, \mathrm{CO}, \mathrm{C}_{2} \mathrm{H}_{2}, \mathrm{CH}_{4}$, and $\mathrm{C}_{2} \mathrm{H}_{4}$; the heat value of the gas is about 5-9 $\mathrm{MJ} / \mathrm{Nm}^{3}$, therefore, it can be used as an efficient fuel source for industrial processes such as power generation. The solid product contains more than $80 \mathrm{wt} \%$ elemental carbon, has a surface area of about $65 \mathrm{~m}^{2} / \mathrm{g}$, and is referred to as pyrolytic carbon black (CBp). X-ray photoelectron spectroscopy (XPS) analysis has revealed that the CBp has mainly graphitic carbon structure similar to those of commercial carbon black. Thus thermal plasma pyrolysis is potentially a useful way of treating waste tires for power generation and carbon black recovery.
\end{abstract}

Key words-thermal plasma; waste tires; power; carbon black; recovery

\section{INTRODUCTION}

In recent years public and political sensitivities to environmental issues and energy security have led to the promotion of indigenous renewable energy resources. Biomass is one of the renewable resources that could play a substantial role in a more diverse and sustainable energy mix. Industrial and municipal wastes including waste tires are often also considered as biomass. A large amount of used tires is produced every year. It is estimated that 2.5 million ton/year are generated in the European Union, 2.5 million ton/year in North America, one million ton/year in Japan, and one million ton/year in China [1]. At present, a considerable portion of waste tires is still being disposed of by using the most common techniques, such as incineration (without the recovery of value) and landfill. Disposal means such as incineration (with the recovery of value), pyrolysis, and gasification have been studied actively. Incineration may utilize the energy content of waste tires, but is associated with the generation of $\mathrm{SO}_{2}, \mathrm{NO}_{\mathrm{x}}$ and other hazardous emissions. Pyrolysis is an alternative disposal method with the possibility for recovery of valuable products from used tires. Conventional pyrolysis of waste tires is usually performed at temperatures from 600 to $1000^{\circ} \mathrm{C}$ and gives rise to gas, liquid and solid products[2-4]. Due to the complexity and poor quality of the pyrolytic products, waste tires disposal by conventional pyrolysis method has not yet gained acceptance in industry.

Thermal plasma pyrolysis offers some unique advantages for solid waste treatment as compared to conventional pyrolysis [5-7]. Since thermal plasmas have high energy density and high temperature, the corresponding reaction times of tires pyrolysis in thermal plasmas are very fast, so that the problems occurred in conventional pyrolysis processes may be alleviated. In this paper, we study the pyrolysis of waste tires in a DC arc plasma reactor with an emphasis on treatment waste tires for power generation and carbon black recovery.

\section{PLASMA PYROLYSIS OF WASTE TIRES}

The experimental setup shown schematically in Fig. 1 consists of two main parts: dc arc plasma generator and the reaction chamber as well as some accessories. The plasma

NNSFC project 50608020 
generator has a tungsten cathode and a water-cooled copper anode with a maximum electric power input of $100 \mathrm{~kW}$.

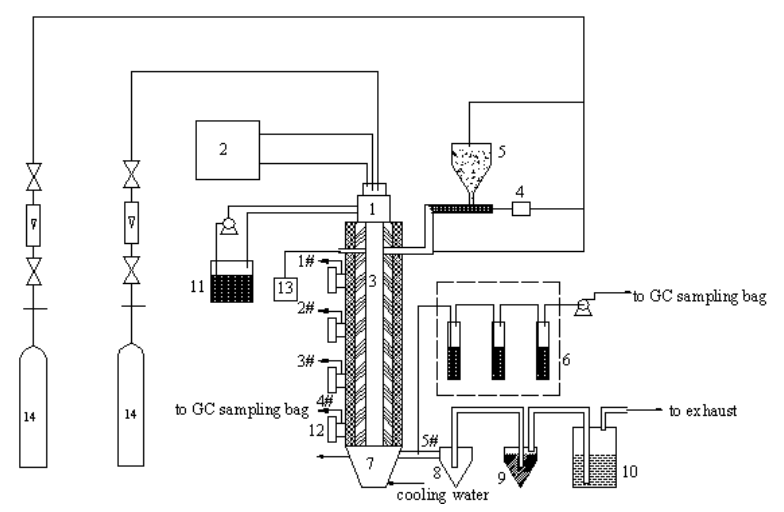

Fig. 1. Schematic of the plasma reactor.

(1.plasma generator 2.control system of plasma generator 3.plasma reaction chamber 4.control system of screw feeder 5.feed hopper 6.gas sampling system 7.ash tank 8.cyclone separator 9.filter 10.water scrubber 11.cooling system 12.observational port 13.water steam generator. 14. nitrogen gas cylinder )

The reaction chamber has a $50 \mathrm{~mm}$ inner diameter and a 1000 $\mathrm{mm}$ height; it is made of $1 \mathrm{Cr} 18 \mathrm{Ni} 9 \mathrm{Ti}$ steel with internal graphite lining. Running water was used to cool the system. Sample particles were put in the reaction chamber by a screw feeder; the particles were heated by the plasma, and the pyrolysis reaction occurred. Water steam can be injected into the reaction chamber when needed. Gaseous product was withdrawn through the sampling line at the exit of the reactor and collected by rubber bags; solid residues were collected in the ash tank.

\section{Characterization of Gaseous AND Solid PROduct}

Experimental conditions and product yields are given in Table 1. It can be seen that two product streams were obtained: a combustible gas and a pyrolytic char in the process; as the input power/feed rate ratio is increased, the gas yield increases, and the solid yield decreases.

The main gas components are $\mathrm{H}_{2}, \mathrm{CO}, \mathrm{C}_{2} \mathrm{H}_{2}, \mathrm{CH}_{4}, \mathrm{C}_{2} \mathrm{H}_{4}$, etc.; the heat value of the gas ranges from 5 to $9 \mathrm{MJ} / \mathrm{Nm}^{3}$, in agreement with the report by Chang et al [8]. In run No. S1, water steam was injected into the plasma reaction chamber together with the tire particles in order to improve product quality and get syngas so that the range of application can be extended. With water steam injection, the amounts of $\mathrm{H}_{2}$ and $\mathrm{CO}$ were increased significantly; the sum of $\mathrm{H}_{2}$ and $\mathrm{CO}$ concentrations reached up to about $38 \%$.

TABLE 1 GAS COMPOSITION (BALANCE $\mathrm{N}_{2}$ ) AND CALORIFIC VALUE FROM PLASMA PYROLYSIS

\begin{tabular}{|c|c|c|c|c|c|c|c|c|c|c|}
\hline \multirow{3}{*}{ No. } & \multirow{3}{*}{$\begin{array}{c}\text { Feed rate } \\
\mathrm{g} / \mathrm{min}\end{array}$} & \multirow{3}{*}{$\begin{array}{c}\text { Power } \\
\text { input } \\
\text { kVA }\end{array}$} & \multirow{3}{*}{$\begin{array}{c}\text { Gas } \\
\text { yield } \\
\%\end{array}$} & \multicolumn{6}{|c|}{ Gas composition } & \multirow{3}{*}{$\begin{array}{c}\text { Gas } \\
\text { calorific } \\
\text { value } \\
\mathrm{MJ} / \mathrm{m}^{3}\end{array}$} \\
\hline & & & & \multicolumn{6}{|c|}{ (Vol. \%, dry basis) } & \\
\hline & & & & $\mathrm{H}_{2}$ & $\mathrm{CH}_{4}$ & $\mathrm{CO}$ & $\mathrm{C}_{2} \mathrm{H}_{4}$ & $\mathrm{C}_{2} \mathrm{H}_{2}$ & others & \\
\hline $\mathrm{F} 1$ & 44.04 & 35.2 & 60.6 & 8.75 & 0.71 & 3.07 & 0.28 & 2.04 & 4.57 & 5.3 \\
\hline $\mathrm{F} 2$ & 89.1 & 35.2 & 42.2 & 14.2 & 1.02 & 3.21 & 0.54 & 3.92 & 5.55 & 7.56 \\
\hline F3 & 96.4 & 35.2 & 40.98 & 18.38 & 0.85 & 3.92 & 0.38 & 2.76 & 5.7 & 7.34 \\
\hline $\mathrm{F} 4$ & 122.5 & 35.2 & 30.98 & 18.54 & 1.01 & 3.27 & 0.54 & 3.6 & 5.1 & 7.94 \\
\hline P1 & 78.06 & 30.8 & 39.68 & 12.07 & 0.71 & 2.75 & 0.25 & 2.57 & 3.6 & 6.76 \\
\hline $\mathrm{P} 2$ & 75.36 & 39.6 & 44.3 & 15.23 & 0.6 & 4.2 & 0.2 & 1.57 & 6.2 & 6.01 \\
\hline P3 & 86.6 & 44 & 43.1 & 15.77 & 0.67 & 4.13 & 0.25 & 1.54 & 6.34 & 6.48 \\
\hline P4 & 80.04 & 48.4 & 45 & 16.15 & 0.69 & 4.25 & 0.27 & 1.42 & 5.83 & 6.12 \\
\hline S1 & 75 & 35.2 & 77 & 24.12 & 0.98 & 14.17 & 0.41 & 1.75 & 6.2 & 8.96 \\
\hline \multirow[t]{3}{*}{ Note: } & : F1-F4 & & & & & Tate & & & & \\
\hline & P1-P4 & - & st with & iffe & III 1 & $P$ & & & & \\
\hline & S1 & & WI & adut & I & tean & & & & \\
\hline
\end{tabular}

Analysis results of solid residue sample from plasma pyrolysis of tire particles are presented in Table 2. The pyrolytic char has surface area comparable with those of medium-grade commercial carbon black though it has a lower carbon content and a larger proportion of ash and impurities than commercial carbon black.

TABLE 2 ULTIMATE AND PROXIMATE ANALYSIS OF SOLID RESIDUE

\begin{tabular}{|c|c|c|c|c|c|c|c|c|}
\hline \multirow[t]{2}{*}{ Materials } & \multicolumn{5}{|c|}{$\begin{array}{l}\text { Ultimate analysis } \\
\text { (wt } \% \text { dried) }\end{array}$} & \multirow{2}{*}{$\begin{array}{c}\text { Ash } \\
(\mathrm{wt} \% \\
\text { dried) } \\
\end{array}$} & \multirow{2}{*}{$\begin{array}{c}\begin{array}{c}\text { Calorific } \\
\text { value }\end{array} \\
\mathrm{kJ} / \mathrm{kg}\end{array}$} & \multirow[t]{2}{*}{$\begin{array}{c}\mathrm{H} / \mathrm{C} \\
\text { atomic } \\
\text { ratio }\end{array}$} \\
\hline & $\mathrm{C}$ & $\mathrm{H}$ & $\mathrm{O}$ & $\mathrm{N}$ & S & & & \\
\hline Tire particle & 80.5 & 7.33 & 10.3 & 0.33 & 1.57 & 8.97 & 37328 & 1.09 \\
\hline CBp1 & 85.1 & 0.24 & 12.4 & 0.38 & 1.97 & 16.25 & 28565 & 0.034 \\
\hline CBp2 & 82.7 & 0.42 & 13.9 & 0.42 & 2.57 & 15.14 & 28703 & 0.061 \\
\hline $\begin{array}{l}\text { CBp from } \\
\text { conventional }\end{array}$ & & & & & & & & \\
\hline pyrolysis $\left(500^{\circ} \mathrm{C}\right)$ & 84 & 0.64 & 0.9 & 0.35 & 2.8 & 12.6 & 28200 & 0.092 \\
\hline $\begin{array}{l}\text { Commercial tire } \\
\text { carbon black A }\end{array}$ & 97.1 & 0.2 & 1.1 & 0.2 & 1.0 & 0.4 & 1 & 0.025 \\
\hline
\end{tabular}

$\mathrm{CBp} 1$ is sample from run No. F2; $\mathrm{CBp} 2$ is sample from run No. S1. 
XPS analysis is used to identify the surface chemistry and carry out a quantitative analysis. Wide-scan spectra in the binding energy (BE) range $0-1000 \mathrm{eV}$ are shown in Fig. 2. The spectra are dominated by the $\mathrm{C} 1 \mathrm{~s}$ photoelectron peak, representing the major constituent of the pyrolytic carbon black. Other smaller signals confirm that oxygen and sulfur are present in the surface region, and weak peaks of other elements such as zinc can be found.

\section{COMMERCIAL USES FOR PRODUCTS}

The product gas is a fuel gas rich in hydrogen and carbon monoxide with a heating value one-quarter to one-third the heating value of natural gas. The hydrogen-rich fuel gas can be used as feedstock for boilers, chillers or fuel cells, of which production of electricity is gaining substantial favour.

Currently, there are two approaches to the generation of electric power in plasma facilities. In the first approach, the combustible gas, or syngas produced in the reactor is burned in a close-coupled combustion chamber and passes the hot gases through a waste heat boiler to generate steam and, subsequently, power. A typical configuration for the generation of electricity with a steam turbine is shown in Figure 3. The energy in the product gas coupled with substantial amounts of recoverable sensible heat throughout the process can generally produce sufficient electricity to drive the process. The provision of dual fuel into the boiler provides versatility for increased amounts of power generation as required.

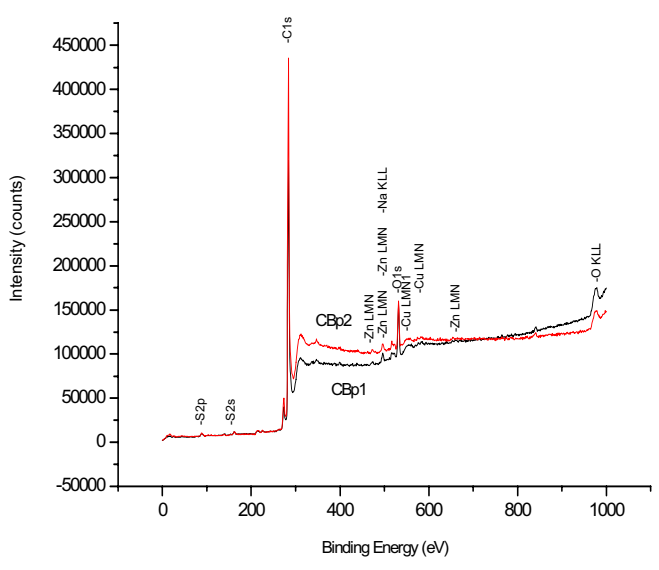

Fig. 2. XPS wide scan spectra $\left(\mathrm{CB}_{\mathrm{p} 1}\right.$ and $\mathrm{CB}_{\mathrm{p} 2}$ sample)

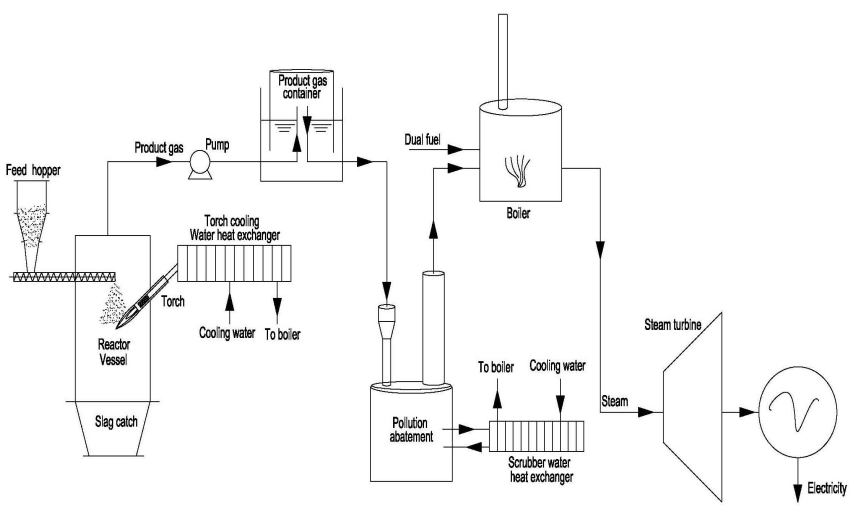

Fig. 3. Electricity generation with waste tires plasma gasification

The second approach to generating power is to use the syngas to fuel a combustion turbine. The burning of the syngas in a combustion turbine combined cycle power plant is more efficient and will typically produce more net power than would be produced using a waste-heat boiler. However, the syngas must be cleaned before it enters the turbine. The combustion turbine combined cycle is typically more difficult to operate than a boiler because the turbine requires gas with a relatively consistent heating value. The addition of supplemental natural gas to the syngas can overcome this problem but it introduces additional complexities and costs to the operation of the facility.

It is well know that a typical waste to energy facility can be expected to produce between $400 \mathrm{kwh}$ and $600 \mathrm{kwh}$ per ton of waste processed. In this process, the combustible gas product as fuel had been considered for power generation, the efficiency $l_{g}$ of the energy conversion from the solid waste tires to gas product can be calculated as:

$$
\eta_{g}=\frac{c_{g} V_{g}}{c_{t} M_{t}} \times 100 \%
$$

Where: $c_{g}$ is the gas product heat value $\left(\mathrm{kJ} / \mathrm{m}^{3}\right), c_{t}$ is the waste tires heat value $(\mathrm{kJ} / \mathrm{kg}), V_{g}$ is the gas product production $\left(\mathrm{m}^{3} / \mathrm{min}\right)$ and $M_{t}$ is the waste tires feed rate $(\mathrm{g} / \mathrm{min}$ ) .

Mean gaseous fuel energy conversion efficiency is about $50 \%$. Based on the performance of other types of gasifiers as 
compared to their combustor counterparts (e.g., coal gasification combined cycle plants), a plasma waste tires disposal facility with a combustion turbine might be more efficient at producing electricity than a state-of-the-art waste to energy plant, but there are no commercial plasma facilities with combustion turbines with which to confirm this supposition.

Because the equipment to produce the electricity is expensive, energy production doesn't make sense unless the feedstock has a high heating value and the throughput is substantial. Nevertheless, the gas product value did not appear sufficiently high to give an economically viable operation; other high value products were required if the conversion process is not to be heavily subsidized. Pyrolytic carbon black with such a high ash content may be used as a semi-reinforcing agent for non-tire rubber applications. Only after further treatment and upgrading can it be used as tire carbon black. For example, about half of the inorganics could be removed from pyrolytic carbon black by a simple acid wash according to Piskorz et al [7]. The sale of other outputs, such as pyrolysis carbon black, will depend on the price for comparable competing materials. Total world production of carbon black is about 6 million tons per year. Most of this is used in the rubber industry as a reinforcing filler. Modern tires contain about $30 \%$ of carbon black. Several dozen different grades are listed by international ASTH classification, where each grade corresponds to a very specific application. Prices vary with quality between $\$ 1000$ and $\$ 4000$ per ton. The grade of the plasma pyrolysis carbon black corresponds to an average structured black, used essentially as reinforcing filler to improved abrasion properties. The average commercial price is about US \$1000-1400 per ton.

\section{PROCESS APPLICATION POTENTIAL}

Our preliminary analysis indicates that plasma pyrolysis of rubber waste has economic potential, given the following assumptions: (1) capital investment for a plant processing rubber waste $300 \mathrm{~kg} / \mathrm{h}$ is $\$ 1500000$; (2) specific energy consumption is $1 \mathrm{kWh} / \mathrm{kg}$ rubber feed; (3) the electricity price for industrial sector is $\$ 0.05 / \mathrm{kWh}$; (4) carbon black recovery is $23 \mathrm{wt} \%$ of rubber feed; market price for semi-reinforcing carbon black is $\$ 500 /$ ton; (5) the gate fee for receiving rubber waste is \$30/ton; and (6) gas yield is $3 \mathrm{Nm} 3 / \mathrm{kg}$ rubber feed, with a calorific value $9 \mathrm{MJ} / \mathrm{Nm} 3$; the gas is combusted in a boiler or gas engine for power generation at efficiency $26 \%$. From the very simple hypothesis presented before, the technology of plasma pyrolysis waste tires for carbon and combustible gases recovery seems to be very interesting.

\section{CONCLUSIONS}

Thermal plasma pyrolysis is in the forefront of modern waste treatment. There is great potential for development of thermal plasma pyrolysis technologies applicable to waste management with energy and material recovery. Although important research progress in this area has been made in recent years, there are still considerable technical challenges to be faced in developing and modifying thermal plasma pyrolysis processes for industrial applications. The rapidly increasing pressure of environmental protection and energy and resources conservation may hasten development and industrial implementation of the technology in the near future.

\section{ACKNOWLEDGEMENT}

We thank NNSFC project 50608020 for financial support.

\section{REFERENCES}

[1] Shulman, V. L. The Recycling in the EU Member States; Spanish Waste Management Association: Madrid, 2000.

[2] Galvagno, S.; Casu, S.; Casabianca, T.; Calabrese, A.; Cornacchia, G. Pyrolysis process for the treatment of scrap tires: preliminary experimental results. Waste Management, vol. 22, pp.917-923, 2002.

[3] Roy, C.; Chaala, A.; Darmstadt, H. The vacuum pyrolysis of used tires: end-uses for oil and carbon black products. J. Anal. Appl. Pyrolysis, vol. 51, pp.201-221, 1999

[4] Piskorz, J.; Majerski, P.; Radlein, D.; Wik, T.; Scott, D.S. Recovery of carbon black from scrap rubber. Energy Fuels, vol. 13, pp.544-551, 1999.

[5] Guddeti R R, Knight R, Grossmann E D. Depolymerization of polyethylene using induction coupled plasma technology, Plasma Chem. Plasma Process, vol.20, pp.37-63, 2000.

[6] Lan Tang, H.Huang, C.Z. Wu, et al., Pyrolysis of Polypropylene in a Nitrogen Plasma Reactor, Industrial and Engineering Chemistry Research. vol.42, pp.1145-1150, 2003.

[7] L. Tang and H. Huang Biomass gasification using capacitively coupled RF plasma technology, Fuel, vol. 84, pp.2055-2063, 2005.

[8] Chang, J. S.; Gu, B. W.; Looy, P. C.; Chu, F. Y.; Simpson, C. J.Thermal plasma pyrolysis of used old tires for production of syngas. J. Environ. Sci. Health A, vol. A31, pp.1781-1799, 1996. 